\title{
Experiment of the South Yakutia Toponymy's Lexicographic Description
}

\author{
Elena Merkel, and Lyubov Yakovleva* \\ Technical Institute (branch) of North-Eastern Federal University, 678960, Kravchenko av., 16, Neryungri, Russia
}

\begin{abstract}
The paper considers main stages of the lexicographic description of the SouthYakutia toponymy. The authors made the classification of collected geographical names in the structural and derivational aspect. During the study, an extra-linguistic analysis of toponyms (geo-referencing, culture-historical information) was conducted. As a result, dictionary entries have been drawn up in which a denomination zone, a zone of interpretation, an etymological and word-forming zone were identified. Different maps as well as Evenk-Russian dictionaries were used as the basic sources for this research. To make the analysis easier, 900 place-names were first categorized and then situated into a special catalogue. As a result, the analysis shows the territorial majority of Evenk placenames what finally proves the wide spread of Tungus tribal people on this territory in ancient times.
\end{abstract}

\section{Introduction}

The process of forming the toponymy of the South Yakut region and its various strata - oikonyms, hydronyms, oronyms, etc. is associated with the formation of peoples, inhabiting this area, their language, way of life, and culture. Each migration wave left here toponymic layers and created its toponymic models. For millennia the historical conditions, languages and peoples have changed, so today we can state the absence of a uniform geographical linguistic range. The historical-genetic approach in the study of the system of South Yakutia toponyms makes it possible to distinguish three main ethno linguistic strata: Evenk-Even, Yakut and Russian.

The relevance of this research is the need to preserve the culture of the people which is reflected in the geographical names as well. Collecting, study and its further systematization of materials into regional dictionaries of local geographical names could serve as one of the means of preserving and transmitting information to subsequent generations. Besides the names of geographical objects in South Yakutia are a largely unexplored area of toponymy.

\section{Materials and methods}

The methodological basis of this research is a complex linguistic approach to the study of regional toponymic material. Techniques used in the study are traditional: the method of scientific description, the method of structural and semantic classification, the method of etymological analysis, the method of statistical and comparative analysis; toponymic identification method.
The sources of actual material were information on the etymology of substratum toponyms collected by the authors during expeditions to the Evenk compact settlements, data from the toponymic card index of the Technical Institute (branch) of the North-Eastern Federal University, Evenk dictionaries, reference books, geographical maps of different years of the publication, the work of historians and geographers who studied the toponymy of Yakutia.

\section{Results and discussion}

The work on the complex analysis of South Yakutia toponymic units included several stages: 1) gathering of toponyms in the study area; 2) the linguistic aspect of the study (etymology, semantics, structure); 3) extralinguistic aspect of the study (geo-referencing, cultural and historical information); 4) compilation of entries (name zone, zone of interpretation, etymological and word-forming zones).

\section{Stage 1. Place-names field collecting in South Yakutia}

At the initial stage of work in the period from 2008 to 2009 , systemic documentation of the toponyms of the Neryungri, Aldan and Olekminsky districts of the Republic of Sakha (Yakutia) was made. The available field vocabulary collected by students during their educational and research work in 1999-2007 and research activities of the staff of the department was identified, resulting in the following:

Corresponding author: merkel-e@yandex.ru 
1. toponyms, for which there was already enough information (a source language, an etymology, the presence of legends);

2. toponyms that have not yet been etymologized.

Collected toponyms were included in the map of the South Yakut region, as well as in the electronic database of toponyms [1]. The toponymic database is characterized by a set of standard data, which is reflected on the toponymic card: toponym, its transcription, the name variants, the type of object, geo-referencing and toponymic legend (or other information about the object recorded during the collection of information including folk-etymological interpretation) and certification (information about the informant, collector, time and place of toponym recording).

\section{Stage 2. Linguistic analysis of toponyms (etymology, semantics, structure)}

At the second stage of the work collected toponymic material was processed in several linguistic aspects: was defined the source language and were carried out toponyms' lexico-semantic and structural-wordformation classifications.

The etymological aspect of the study made it possible to disclose the origin and interpretation of South Yakutia toponyms. The work was complicated by several factors. More than $50 \%$ of toponyms are aboriginal origin. Besides the heterogeneity of geographical names by origin they also characterized by heterogeneity by the time of origin. It can be explained by the fact that the territory has constantly served as a place of contact and coexistence of related and unrelated ethnics.

Textual discrepancy in the designation of a particular topographic object had made the work more difficult, the reason of which was the result of the multilingualism in the region. Thus, the phonetic and graphic changes that toponyms undergo in the transition from one language to another are due to the peculiarities of the interaction of the three linguistic systems (Evenk, Yakut and Russian). For example, long vowels, diphthongs in geographical names of Yakut and Evenk origin are transmitted by one sound; the sounds missing in the successor language are replaced by similar sounds in articulation, etc. In that regard, in the literature there is frequent difference in the transfer of geographical names borrowed from the indigenous languages of South Yakutia.

Another factor complicating the work at this stage is connected with difficulties, sometimes insurmountable, in the etymology of toponyms. Its reasons are, first, the major part of the toponyms is represented by the names of hydro- objects (hydronyms), which as known, have a later origin relative to other types of toponyms and, as a result, have a complex etymologization process. Secondly, to some extent, the difficulty in interpreting toponyms is due to increasing number of aboriginals, primarily the Evenks, who do not speak their native language.

The information given by informants was carefully checked by several sources (work with Evenki-Russian, Russian-Evenki, Russian-Yakut, Yakut-Russian toponymic dictionaries, publications on toponymy). In some cases the etymology, given by the informant, have not been confirmed, was erroneous.

The work with maps of the early years publication $(1922,1929,1952$, etc.) and the identification of variants of geographical names facilitated the clarification of toponyms' language and their interpretation. Variation of several names of one toponymic unit is a characteristic feature of South Yakutia toponymy. This is due, first of all, to the close interaction of several languages in this territory.

The largest group of the South Yakutian geographical names due to their origin was the names of the TungusManchurian (Even-Evenki) origin, what can be explained by the fact that before the advent of Mongolspeaking, Turkic-speaking and Russian peoples, the aborigines of the region were the Tungus-Manchurian tribes.

The names of the Yakut and Russian origin are presented in a less quantitative group.

The peculiarities of the South Yakutia toponymic system include the names of hybrid origin, for example, words with the Evenki stem and the Russian suffix (Elkonka, Yukhtochka, Seligdarsk, Kankunsky) or words with the Russian stem and the Evenki suffix (Slyudakai), etc.

At the same stage, a semantic classification of the South Yakutia toponyms was carried out, what made it possible to identify the physical and geographical characteristics of the terrain and to obtain certain information about what activities population was employed in, directly or indirectly reflected in the semantics of toponyms, and also to clarify the basic principles of toponymic nomination.

Semantic classification, proceeding from the belonging of names to common words and anthroponyms, to which they appeal, was taken as the basis [2]. Semantic analysis made it possible to distinguish the following. Undoubtedly, the vast majority of geographical names refers to appellative ones. Anthropotoponyms are represented to a lesser extent in the toponymic space of South Yakutia, and in most cases they are toponyms of Russian origin. For example, the Alekseevsk village; the Zverev ridge, the Semenovsky stream, and others.

All appellative aboriginal names unite their natural or everyday activity basis. It is possible to speak of the five main criteria underlying the classification of toponyms of aboriginal origin.

1. Geographical names reflecting the features of the locality in which the geographical object is located. Such toponyms as Alarangy Yuryakh ("the river below"), Altan-Chaydakh ("river with pebbled shore, in which there is copper"), Argaa-Salaa ("western inflow"), Kuchchugui-Kustur ("a place where abundant hunting for waterfowl"), etc. This group includes most of the South Yakutia oikonyms, because they are due to the rivers near which settlements are located (Neryungri, Olekminsk, Aldan, Iengra, Chulman, Upper and Lower Kuranakh, etc.).

2. Names which reflect the qualitative features of geographical objects. This group of toponyms is no less 
numerous than the previous one. Examples of toponyms: Kieng-Yuryakh ("wide river"), Kuchchugui ("small island"), Sinniges ("narrow river"), etc.

3. Phytotoponyms are names based on vegetation species. Phytotoponyms include the following South Yakutia geographical names: Bestyakh ("a river on the banks of which pine grows"); Sibikte-Aryy ("horsetail island"), etc. A lot of toponyms are formed by names based on the Yakut appellative khatyn (birch): KhatynYuryakh, Khatyn-Tumul, Khatyn-Sysy, Khatyn-Ary, Khatyngnaakh and others.

4. Zootoponyms are names, based on animal species. For example, on the territory of South Yakutia, where water is rich in fish, hydronyms formed according to the species of fish are widespread: Alasyrdakh ("perch lake"), Dekonda ("perch river"), Kuchchuguy Sugdzhu ("small river full of salmon or lenok"), Mundu-Kuel ("minnow lake "), Delingne ("taimen river "), etc.

5. Geographical names related to Evenks or Yakuts' life and daily graft: Allara Balagannakh ("the lower river with the balagans (dwellings)"), Kolbochi ("the river near which there are high-seats for hunting"), Saaybalaakh ("river with a log cabin for storing fish") and others. We must also mention a group of toponyms, the values of which are related to the action: AllaraSasyl-Siebit ("the place where the fox was hunted") and the same rooted hydronyms such as Ortho-Sasyl-Siebit and Yousse-Sasyl-Siebit, in which oronym is Siebit.

As for toponyms of Russian origin, from the semantic characteristic point of view, they can have similarities with aboriginal toponymic vocabulary, as well as differences [3]. Integral features include the above-mentioned principles of nomination of topoobjects. The differential principles include such principles of nomination as ideological, trade and transport and social: the collective farm named after Kirov, the Comintern, Komsomolskaya, Krasnaya Zvezda, the village of YATSIK, the boat yard of the LORP, the Corporal, the Radio Mountain, etc.

Also, at the second stage of the project, structural and word-formation features of the South Yakutia toponyms were considered [4]. It is worth noting that in the South Yakutia toponymic space there are both simple and compound topo-units.

Simple toponyms are available in all languages. For example, Russian toponyms (Corporal, Steep, High, Swamp, Big, Nagorny, etc.); Evenki toponyms (Solokit, Berkakit, Birikyan, Kudukta, Naaldy, etc.); Yakut toponyms (Sordongnokh, Boru, Buordakh, Kyuellay, etc.).

The main methods of hydronyms formation (suffixation, conversion), oikonyms (transfer of settlement name, suffixation), oronyms (suffixation, conversion, transfer of uplands name) are determined.

Particular attention was paid to topo-formants, since in aboriginal languages the status of affixing morphemes is not the same. So, if in Russian language suffixes do not carry any independent semantic meaning, then, for example, in the Evenki language, each suffix gives a certain meaning to geographical name. For example, the name of the Amnukachi River, which includes the suffix -chi, is translated as "the river with glare ice," the cognate hydronym Amnunnali, due to the suffix -li, the "river along which glare ice everywhere" matters.

Compound names in most cases are hybrid : a) junction of the Russian adjective with the Evenki or Yakut noun (Bolshoy Toko, Nizhni Kuranakh); b) junction of the Yakut adjective with the Evenki noun (Ulakhan-Myolyomkyon); c) junction of the Yakut adjective with the Evenki adjective (UlakhanNierichchi). The existence of all those hydronyms can be explained by the multi-ethnicity of the Neryungri district. The functioning of hybrid names forms a feature of the toponymic system of this region.

It should also be noted that among the compound toponyms you can often meet names of Yakut origin, including nomenclature geographical terms. For example, in the names of uplands, the Yakut term "khaya" is used: "mountain ridge, mountains": AbahyKhaya, Ingyr-Khaya, Bayanay-Khaya, etc. The names of rivers may include the yuryakh component - from the Yakut language "river ": Doidu-Yuryakh, Bes-Yuryakh, Kurung-Yuryakh, etc. For Evenk toponymy, in particular, hydronymics, this phenomenon is not typical, mostly because of the suffix -ngna and its variants dngra, -negda, -ngra, - nndya, -nnya, meaning "river" or "terrain", which is added to the name of any fish, animals, plants, metals, is characteristic for a given river, lake or locality. For example, Iengra, Neryungra, Davangra, Nychangda, etc.

The structure of the derived toponym with a complex stem from the point of view of its producing part of speech is mostly represented by three varieties:

1. adjective + noun (Kurung-Yuryah, Bolshoe Toko),

2. adjective + adjective (Nizhnyaya Talum, UlakhanNierichchi)

3. noun + noun (Ese-Khayata, Shaman-mountain).

\section{Stage 3. Performing extra linguistic analysis of toponyms (geo-referencing, culture-historical information)}

The extra linguistic analysis of the collected toponymic material suggested the determination of the geographic object's binding to the locality and culture-historical information.

The study of names in the geographical aspect caused certain difficulties. First, in the topographic maps and schematic maps used in our work, in some cases, the type of object (stream, river, spring, etc.) is not indicated. Secondly, the maps do not always have the direction of the water body flow, which also made it difficult to determine the accurate geo-referencing.

Working with archives allowed enriching information of toponyms with documentary information about formation, renaming, changing the status of the topo-object. It should be noted that changes in the names of geographical objects in the region under study are primarily related to intensive and long-term processes of development of this territory by peoples belonging to different linguistic groups (Tungus-Manchu, Turkic and Slavic). 


\section{Stage 4. Dictionary entries drafting (denomination zone, interpretation zone, etymological zone)}

The specific target within the problem of complex analysis of the South Yakut region toponyms, to which the project was directed, was to compile a regional toponymic dictionary of South Yakutia.

The final version of the dictionary contains the interpretation of 788 geographical names, including hydronyms (names of rivers, lakes and streams) - 486, oikonyms (names of settlements, including uninhabited ones) - 168, oronyms (names of uplands) - 112, nesonyms (names of islands) - 22. The main factor influencing the selection of certain toponyms was the degree of popularity of the place-name (size, economic significance, historical value / notability). Outside the vocabulary there were microtoponyms, that is, names of small objects, for example, some streams, swamps, wetlands, etc.

The entries are arranged in an alphabetical order. If the place-name has Russian differentiating determinants large - small, upper - lower, etc., then they are included in the dictionary by the main name, for example, Amga: Amga Upper and Amga Lower. Unfortunately, it was not possible to realize the same principle of location in the dictionary of toponyms containing differentiating determinants of the Yakut or Evenki languages, in view of the frequent cases of complete formality in these languages of the differentiating determinant and the main toponym (Ulakhan-Ary ("big island"), UngaSytygan "Right Sytygan"), Kuchchuguy-Kustur "a small place where there is a good hunt for waterfowl", Allaraa-Siikay ("the lower tributary stream of the unfreezing river"), etc.).

Toponyms that are collocations such as "nomenclature term + noun in the genitive case" are located in the dictionary for the first component. Thus, the Zverev ridge is included in the section " $R$ ", the village of the name YATSIK - in the section "V", etc.

The characteristic of each toponym is presented in the dictionary entry, which has the following structure [5-10].

1. The entry word is a current official name in its original form. In this part of the dictionary entry, after a slash, there are also its written or spoken variants. Mostly, these variants are not found in everyday speech, but in time-varying maps only. In our vocabulary all previous and existing variants of the nomination of the object are recorded, which are combined in one dictionary entry into a kind of toponymic series, the first in it is the place-name presented on the map of the later edition. For example, Algama (1991, 2009) / Algoma (1951).

In case of renaming an object after the official name, the former, already outdated, nomination is passed through two slashes (Aldan // Nezametnuy).

In cases where the name is common to a river and, for example, a settlement, the dictionary entry of hydronym is preceded by the others, because the name of the river is most often primary: for example, Chulman (river) - Chulman (village).
The entry word is accompanied by normative and grammatical marks: stress, gender and declension are indicated. The type of declension is indicated for the toponym, functioning in the text without the nomenclatural term.

For two-word toponyms, the declension is indicated for the stem word.

If the grammatical features of compound toponym components do not coincide, declension is indicated by two marks. For example, the toponym Kurung-Yuryakh accompanies two grammatical marks: indecl., $-a$. The first characteristic relates to the component Kurung, which does not incline in the compound of this place name. The second component, Yuryakh, changes according to the second type of declension of nouns: Yuryah- $a$ (genitive singular), etc. If both components of the toponym do not change, one general mark is given: indecl.

If the place-name has nomination variants, different in their grammatical features, grammatical marks are given only for the official name. For example, Delinde, $f$., indecl. / Jelinda.

In some cases, when morphological features are difficult to determine unambiguously, mostly because of rare use of the toponym, i.e., without the nomenclatural term, grammatical marks are accompanied by a question mark.

2. Interpretation (explanatory- encyclopedic zone) is information about the type of the object, its coordination on the locality (in some cases with a brief characteristic). Describing the nature of the object, abbreviations were used, the list of which is given at the beginning of the dictionary.

3. History-etymological reference is information about the origin of the place-name, its etymology including its sources. Meanwhile, if there are different versions of the toponym origin, all known variants of the explanation are given, including folk etymology. Other interesting assumptions are also given. The description of some toponyms is accompanied by a brief historical and ethnographic reference.

Describing the etymology of toponyms of aboriginal origin, the transmission of the words of Yakut or /and Evenk languages is carried out, if possible, with the letters of the corresponding alphabet or by using various graphic signs.

4. Illustration. In this part of the dictionary entry there are examples of the toponyms using in speech in most cases documented. The main sources are literary texts, newspaper articles, Internet publications.

Obviously, not every dictionary entry reaches the necessary completeness. The lack of information made for a number of names only a short etymological reference. The dictionary entries of the toponyms of the Yakut and Evenki origin have a larger volume, since the etymology of the word, its derivational features are described in detail; in some cases, several versions of the origin of the toponym are given, the folk-etymological interpretation, cultural and ethnographic information related to this or that object. For example:

Tyubya, f.,-i./ Tyuba (1952). Rural settlement on the territory of the Malzhagar nasleg of the Olekminsky 
ulus. Located $15 \mathrm{~km}$ from the ulus center Olekminsk, distance to the nasleg center Yunkyur is $8 \mathrm{~km}$ away. It is included in the list of hard-to-reach and remote areas of the republic. The word is etymologized by means of the Yakut language: tyubya - "distant village, wilderness, hinterland ". Thus, it can be assumed that the name is related to the location in a remote place [102, p. 49]. Local residents translate the word tüba as "a swamp place, a marsh " (Filippov AN), in translation from the Yakut tyuebe means "thick, dense forest, midwood (usually above the river)" [11].

Toponyms of Russian origin are revealed by the simplified structure of the dictionary entry: official name, geo-referencing, free (often literal) transfer of meaning. For example, Polovinka, f, -i. The left inflow of the river. Gorbyullakh, Neryungrinsky region. Hydronym of Russian origin. According to local residents, the river flows halfway from the one nomads camp to another one. It was the place where reindeer herders and hunters stayed for a rest. It should be noted the wide spread of toponyms with the name Polovinka both on the territory of the Republic of Sakha (Yakutia) and Russia: wintering Polovinka, station Polovinnaya in the Olekminsky ulus, village Polovinka in the Irkutsk oblast is halfway between the villages of Ust-Kut and Podymakhino, river The Great Polovinnaya at Lake Baikal, which divides in half the shore of Lake Baikal from the headstream of the Angara to the southeastern tip of the lake and others [11].

The dictionary contains a reference list, which includes 160 sources, footnote to which within the entries is given in brackets.

There is a short terminological dictionary in the appendix (includes 26 terms), which makes it easier to work with the text of the dictionary.

\section{Conclusion}

As a result of the research, the most commonly used principles of nomination in the Yakut and Evenk toponyms are identified: a feature of a geographical object; the features of the locality in which the geographic object is located; type of vegetation or plant species; fauna within the geographical location; local employment. For Russian toponyms, in addition to the listed principles of nomination of topo-objects, ideological and social principles are also typical. Among the topolexemes of Russian origin, to a greater extent than in aboriginal toponymy, anthroponymic names are common.

Classification of collected place-names in the structural and derivational aspect is made. As the analysis has shown, in the territory of South Yakutia the most common are simple toponyms. The main methods of formation of hydronyms (suffixation, conversion), oikonyms (transfer of the name of settlements, suffixation), oronyms (suffixation, conversion, transfer of the name of uplands) are determined. A number of the most regular Yakut and Evenki suffixal topoformants and their meanings were revealed. The dictionary entries of toponyms have been drafted, and from 820 toponyms
788 ones are supplied with dictionary entries, 486 of them are hydronyms (names of rivers, lakes and streams), 168 oikonyms (names of settlements, including uninhabited ones), 112oronyms (names of uplands), 22 nesonyms (names of islands). The number of dictionary entries of the toponyms of Neryungri region was 226 units, Aldan ulus - 291, Olekminsky - 271.

The dictionary of the South Yakutia toponyms was developed and prepared for publication, including, in addition to dictionary entries, a foreword, a short terminological dictionary, which includes 26 terms used in the drafting of entries, and a reference list, which includes 160 sources.

\section{References}

1. V.L. Vasiliev, N.N. Vikhrova. Issues of onomastics 1(18), 84-107 (2015).

2. E.L. Berezovich, Semantic typology of Russian toponyms: problems, questions, opportunities, prospects. Onomastics and dialect vocabulary: a collection of scientific papers (Ural University Press, Ekaterinburg, 1998)

3. E.L. Berezovich, Russian toponymy in the ethnolinguistic aspect (Ural University Press, Ekaterinburg, 2000)

4. E.O. Borisova, Ju.A. Krivoshchapova, V.S. Kuchko, N.A. Sinitsa, Issues of onomastics 2(15), 174-199 (2013)

5. K.A. Gein, Issues of onomastics 1(10), 196-199 (2011)

6. K.A. Gein, Issues of onomastics 2(17), 68-77 (2014)

7. N.V. Kabinina, Substrate toponymy of Arkhangelsk Pomorie (Ural University Press, Ekaterinburg, 2011)

8. V.V. Morkovkin, Experience of ideographic description of vocabulary (Analysis of words with the meaning of time in Russian) (Publishing house of Moscow University, Moscow, 1977).

9. I.I. Mullonen, Toponymy of Zaonezhye. Dictionary with historical and cultural comments (Karelian Research Center RAN, Petrozavodsk, 2008)

10. M.E. Ruth, An imaginative nomination in Russian onomastics (Publishing house LKI, Moscow, 2008) 